\title{
Research Highlights From the Asian Seas International Acoustics Experiment in the South China Sea
}

\author{
James F. Lynch, Senior Member, IEEE, Steven R. Ramp, Ching-Sang Chiu, Tswen Yung Tang, Ying-Jang Yang, \\ and Jeffrey A. Simmen
}

\begin{abstract}
The Asian Seas International Acoustics Experiment (ASIAEX) included two major field programs, one in the South China Sea (SCS) and the other in the East China Sea (ECS). This paper summarizes results from the work conducted during April and May 2000 and 2001 over the continental shelf and slope in the northeastern South China Sea, just east of Dongsha Island (Pratis Reef). The primary emphasis of the field program was on watercolumn variability and its impact on acoustic propagation loss. The reader is steered to the appropriate paper within this Special Issue when more information on a specific topic is desired.
\end{abstract}

Index Terms-Acoustic propagation, Asian Seas International Acoustics Experiment (ASIAEX), internal waves, ocean currents, South China Sea.

\section{INTRODUCTION}

$\mathbf{S}$ EVERAL of the papers in this Special Issue resulted from work performed during the Asian Seas International Acoustics Experiment (ASIAEX). This large multi-institutional, multi-disciplinary experiment was executed in both the East and South China Seas during 2000-2001. This paper serves as an overview and introduction to the South China Sea (SCS) component of the experiment, conducted by a team of scientists from the U.S., Taiwan, and Singapore. For a similar overview of the East China Sea results, the reader is referred to Dahl et al. [1].

The primary goal of the SCS component of ASIAEX was to understand acoustic interaction with the ocean volume in the presence of strong variability. The experiment represents a progression from previous, similar coupled physical oceanography and acoustics experiments such as the Shallow-Water Acoustic Random Media (SWARM) [2] and Shelfbreak PRIMER [3] programs on the east coast of the U.S. Due to resource limitations, both of these previous experiments studied the vertical properties of sound propagation at two narrow frequency bands. With the addition of more sophisticated sources and a new L-shaped hydrophone array possessing both vertical and horizontal apertures, the ASIAEX SCS program sampled the horizontal properties of the sound field as well, over the entire low-frequency band up to $600 \mathrm{~Hz}$.

The study region centered near $21.9^{\circ} \mathrm{N}, 117.2^{\circ} \mathrm{E}$ was chosen because it encompassed the continental shelfbreak and dis-

This paper is part of the Guest Editorial for the Special Issue on Science and Engineering Advances in Exploring the Asian Marginal Seas.

Digital Object Identifier 10.1109/JOE.2005.843162 played interesting mesoscale and finescale oceanography that would strongly affect acoustic propagation at low frequencies. The oceanographic variability was driven at the mesoscale by the monsoonal wind stress, buoyancy fluxes from the Chinese coast, and by occasional Kuroshio intrusions through the Luzon Strait [4]-[6]. The semidiurnal and diurnal tides are both quite energetic and highly variable across the region [7]-[11]. At the finer spatial scales, the dominant oceanographic process was the highly energetic nonlinear internal waves. While these waves had been previously observed [12]-[14], a detailed in situ study sufficient to describe their energetics and dynamics had not been obtained.

The field program was executed over the course of 15 research cruises (Table I), six during the year 2000 pilot study and nine during the main field program. All the cruise were executed from the Taiwanese research vessels Ocean Researcher 1 (ORI), Fisheries Researcher 1 (FRl), and Ocean Researcher 3 (OR3) operated by the National Taiwan University, the Taiwan Fisheries Research Institute, and the National Sun Yat-sen University, respectively. The physical oceanography moorings and SeaSoar towed vehicle work were done from the $O R l$, the heavy acoustics moorings from the $F R l$, and the underway acoustics and towed CTD (conductivity, temperature, and depth sensor) work from the $O R 3$.

The general chronology of events can be seen from Table I. Following a longer exploratory deployment, the rapid-sampling pilot study moorings were deployed in early April 2000 and recovered in early May, with SeaSoar (0-350 m) and deep CTD surveys conducted while they were in the water. During the main field experiment in 2001, the basic premise was once again to deploy the moorings, survey the area using a variety of sampling tools, and then recover the moorings at the end. The experiment was necessarily short (April-May) to allow for very rapid sampling and to limit losses from the very heavy fishing activity in the region, but was sufficient to sample an entire spring/neap tidal cycle. The contributions of the various principal investigators is summarized in Table II.

\section{Summary of PhysicAl OCEANOGRAPHY Results}

The principal sampling suites deployed include the moored array [15], the SeaSoar surveys [16], the high-frequency acoustics and towed CTD surveys [17], and satellite remote sensing, 
TABLE I

Chronology of the ASIAEX SCS RESEARCh CRUISES

\begin{tabular}{|c|c|c|c|}
\hline Date & Ship & Chief Scientist & Objective \\
\hline 7-20 April, 1999 & R/V Ocean Researcher I & Dr. Tswen Yung Tang, NTU & Oceanic mooring deployment $\&$ recovery \\
\hline 6-12 April, 2000 & R/V Ocean Researcher I & Dr. Tswen Yung Tang, NTU & Oceanic mooring deployments \\
\hline 14-25 April, 2000 & R/V Ocean Researcher I & $\begin{array}{l}\text { Dr. Joe Wang, NTU } \\
\text { Dr. Glen Gawarkiewicz, } \\
\text { WHOI }\end{array}$ & SEASOAR surveys \\
\hline $\begin{array}{l}28 \text { April-13 May, } \\
2000\end{array}$ & R/V Ocean Researcher I & Dr. Yiing Jang Yang, NTU & Oceanic mooring recoveries \\
\hline 25-28 April, 2000 & R/V Ocean Researcher III & Dr. Ming-Kuang Hsu, NTOU & CTD surveys \\
\hline $\begin{array}{l}\text { 16-20 September, } \\
2000\end{array}$ & R/V Ocean Researcher III & $\begin{array}{l}\text { Dr. Ruey-Chang Wei, } \\
\text { NSYSU }\end{array}$ & Topography surveys \\
\hline 19-25 April, 2001 & R/V Ocean Researcher I & $\begin{array}{l}\text { Dr. Yiing Jang Yang, CNA } \\
\text { Dr. Ching-Sang Chiu, NPS }\end{array}$ & Oceanic mooring deployments \\
\hline 1-12 May, 2001 & R/V Ocean Researcher I & $\begin{array}{l}\text { Dr. Joe Wang, NTU } \\
\text { Dr. Glem Gawarkiewicz, } \\
\text { WHOI }\end{array}$ & SEASOAR surveys \\
\hline 16-23 May, 2001 & R/V Ucean Researcher i & $\begin{array}{l}\text { Dr. Yiing Jang Yang, CNA } \\
\text { Dr. Steven R. Ramp, NPS }\end{array}$ & Oceanic mooring recoveries \\
\hline 25 April-1 May, 2001 & R/V Ocean Researcher III & $\begin{array}{l}\text { Dr. Ruey-Chang Wei, } \\
\text { NSYSU } \\
\text { Dr. Marshall Orr, NRL }\end{array}$ & $\mathrm{J}-15$ source tows \\
\hline 4-10 May, 2001 & R/V Ocean Researcher III & $\begin{array}{l}\text { Dr. Chau-Chang Wang, } \\
\text { NSYSU } \\
\text { Dr. Steve Wolf, NRL }\end{array}$ & Two-yo CTD surveys \\
\hline 14-19 May, 2001 & R/V Ocean Researcher III & $\begin{array}{l}\text { Dr. Ruey-Chang Wei, } \\
\text { NSYSU } \\
\text { Dr. Steve Wolf, NRL }\end{array}$ & $\mathrm{J}-15$ source tows \\
\hline \multirow[t]{2}{*}{28 April-4 May, 2001} & R/V Fisheries Researcher I & $\begin{array}{l}\text { Dr. Shao Sheng Chyn, TFRI } \\
\text { Dr. Tswen Yung Tang, NTU }\end{array}$ & Acoustic mooring deployments \\
\hline & & Dr. Jim Lynch, WHOI & \\
\hline 17-24 May, 2001 & R/V Fisheries Researcher I & $\begin{array}{l}\text { Dr. Shao Sheng Chyn, TFRI } \\
\text { Dr. Tswen Yung Tang, NTU } \\
\text { Dr. Jim Lynch, WHOI }\end{array}$ & Acoustic mooring recoveries \\
\hline $\begin{array}{l}24 \text { March-6 April, } \\
2003\end{array}$ & R/V Ocean Researcher I & $\begin{array}{l}\text { Dr. Char-Shine Liu, NTU } \\
\text { Dr. Louis R. Bartek, UNC }\end{array}$ & Geological surveys \\
\hline
\end{tabular}

List of acronyms:

CNA: Department of Marine Science, Chinese Naval Academy

NPS: Department of Oceanography, Naval Postgraduate School

NRL: Naval Research Laboratory

NSYSU: Institute of Undersea Technology, National Sun Yat-sen University

NTOU: Department of Oceanography, National Taiwan Ocean University

NTU: Institute of Oceanography, National Taiwan University

TFRI: Taiwan Fisheries Research Institute

UNC: University of North Carolina

WHOI: Woods Hole Oceanographic Institution

especially using the synthetic aperture radar (SAR) [18]. A complete list of the mooring positions, instrumentation used, start and stop times, sampling schemes, etc., may be found in Table I in [15]. Progressing from the largest to the smallest scales, a few of the highlights from the experiment are summarized below. Additional details may be found in each of the referenced papers in this issue.

The mesoscale variability during 2000 and 2001 was compared using the SeaSoar and large-scale CTD surveys [16]. They found that the mean flow was quite different during the two years, with a stronger $(0.9 \mathrm{~m} / \mathrm{s})$ northeastward flow over the shelf and slope during 2000 and a weaker $(0.2 \mathrm{~m} / \mathrm{s})$ southwestward flow during 2001. They attributed the difference to a much colder winter during 1999-2000, which set up a stronger density contrast across the shelf/slope front. The flow also was quite sensitive to the extent of the Kuroshio intrusions during any given year and to the location of the bifurcation point for the Kuroshio onslope flow [19]. Significant interannual variability can therefore be expected in the ASIAEX study region.

The tides in the area were mixed, with the $\mathrm{O} 1$ and $\mathrm{K} 1$ tidal currents dominant over the upper slope and the M2 tidal current becoming dominant over the shelf [20]. The tidal currents were elliptical at all sites, with clockwise turning with time with the possible exception of $\mathrm{O} 1$ and $\mathrm{K} 1$ constituents over the slope where the semi-minor axes were poorly resolved. The $\mathrm{O} 1$ and $\mathrm{K} 1$ current amplitudes tended to increase slightly northward toward the shelf break and then decrease toward shallower water over the shelf. The $\mathrm{O} 1$ and $\mathrm{K} 1$ transports decreased monotonically northward by a factor of 2 due to the sharp decrease in water depth from the deepest slope site to the shallowest shelf site [20]. The $\mathrm{O} 1$ and $\mathrm{K} 1$ energy fluxes were directed roughly westward over the slope and eastward over the midshelf. The barotropic M2 and S2 current ellipses turned 
TABLE II

ASIAEX 2000-2001 SCS PRINCIPAL INVESTIGATORS, LISTED ALPHABETICALLY BY INSTITUTION

\begin{tabular}{|c|c|}
\hline \multicolumn{2}{|c|}{ Chinese Naval Academy } \\
\hline Yiing-Jang Yang & Current Meter Moorings \\
\hline \multicolumn{2}{|c|}{ Florida Atlantic University } \\
\hline Steve Schock & G\&G, Bottom Surveys \\
\hline \multicolumn{2}{|c|}{ NASA Goddard Space Flight Center } \\
\hline Tony Liu & SAR Imagery \\
\hline \multicolumn{2}{|c|}{ National Sun Yat Sen University } \\
\hline Chau Chang Wang & CTD Surveys \\
\hline Ruey-Chang Wei & Acoustics, CTD Surveys \\
\hline \multicolumn{2}{|c|}{ National Taiwan University } \\
\hline Chi-Fang Chen & Acoustics \\
\hline \multicolumn{2}{|l|}{ Char-Shine Liu } \\
\hline David Tang & Current Meter Moorings \\
\hline Joe Wang & SeaSoar Surveys \\
\hline \multicolumn{2}{|c|}{ National Taiwan Ocean University } \\
\hline Ming-Kuang Hsu & CTD Surveys \\
\hline \multicolumn{2}{|c|}{ National University of Singapore } \\
\hline Eng Soon Chan & CTD Surveys, Numerical Modeling \\
\hline John Potter & Acoustic, PANDAs \\
\hline \multicolumn{2}{|c|}{ Naval Postgraduate School } \\
\hline Ching-Sang Chiu & Acoustics Moorings \\
\hline Steve Ramp & Current Meter Moorings \\
\hline \multicolumn{2}{|c|}{ Naval Research Laboratory } \\
\hline Peter Mignerey & Underway Acoustics, Towed CTD \\
\hline Marshall Orr & Underway Acoustics, Towed CTD \\
\hline Bruce Pasewark & Underway Acoustics, Towed CTD \\
\hline Steve Wolf & Underway Acoustics, Towed CTD \\
\hline \multicolumn{2}{|c|}{ University of North Carolina } \\
\hline Lou Bartek & G\&G, Bottom Surveys \\
\hline \multicolumn{2}{|c|}{ Woods Hole Oceanographic Institution } \\
\hline Mike Caruso & Satellite SST, Altimetry \\
\hline Tim Duda & Current Meter Moorings, LOCO Moorings \\
\hline Glen Gawarkiewicz & SeaSoar Surveys \\
\hline Jim Lynch & Acoustics Moorings \\
\hline
\end{tabular}

clockwise in the onshelf direction, with a clear onshelf increase in current amplitude. The M2 and S2 transport ellipses also showed this clockwise veering, but with little change in amplitude, suggesting that the flow was approximately nondivergent in the direction of the ellipse orientation [20]. The M2 energy flux vector was generally closely aligned with the transport major axis and within $6 \%$ of its maximum value, a result of the small phase lag between high water and maximum transport. Thus, the M2 tide (and to a lesser extent the S2) appeared to be turning clockwise to become more across the local isobaths as it moved northward into shallower water, like a local plane wave undergoing refraction and topographic steering yet conserving energy along its path. This accounts for the onshelf increase in M2 current components and their dominance of the tidal variance on the shelf. The observed results were generally consistent with recent theory [11], [21].

A detailed analysis of the internal tide shows that diurnal waves were likely generated locally between the 350 - and $200-\mathrm{m}$ isobaths [22]. The bottom slope $\left(0.1-0.3^{\circ}\right)$ in this region was critical for generating diurnal internal waves but not semidiurnal waves [22]. The ratio of the energy fluxes for the baroclinic to barotropic diurnal tide was about $8 \%$, indicating significant local energy conversion [20], [22]. The semidiurnal internal tide is assumed incoming from the Luzon Strait, which is one of the global hot spots for M2 barotropic to baroclinic energy conversion [23].

Four papers in this volume attacked the difficult problem of characterizing the highly nonlinear high-frequency internal waves in the region [15], [18], [22], [24]. Waves with amplitude exceeding $100 \mathrm{~m}$ were observed during both the pilot studies [24] and the main field program [15]. The waves during 2001 arrived in two clusters of $8-9$ d separated by a period of 4-5 d when no waves were observed. In each cluster, the largest waves arrived diurnally with smaller packets in between arriving semi-diurnally.

The wave shapes were highly distorted, looking much like the waves that are often referred to as solitons or soliton packets in the literature (Fig. 1). The waves were all depression waves over the continental slope $(H>350 \mathrm{~m})$ and induced positive temperature fluctuations greater than $10^{\circ} \mathrm{C}$ at a 120 -m depth [Fig. 1 (bottom)]. The lead Soliton often, but not always, split into two smaller peaks as the wave shoaled from a 350- to 200-m bottom depth (Fig. 1 (middle)). In shallow water over the continental shelf $(H<80 \mathrm{~m})$, elevation waves appeared, which lifted bottom water to near the surface forcing a $5{ }^{\circ} \mathrm{C}$ drop in temperature at 40-m depth (Fig. 1 (top)). The transition region where the upper and lower layer thicknesses were equal varied between the 80-120-m isobaths, depending on the phase of the internal tide. In the elevation waves, the polarity of the waves was reversed.

All the waves were mode- 1 internal waves with the exception of a single mode- 2 wave observed during April 10, 1999 [24]. The largest waves propagated WNW at around $1.5 \mathrm{~m} / \mathrm{s}$, in the direction of the upper layer orbital velocity. The maximum wave velocities were order $1.6 \mathrm{~m} / \mathrm{s}$ in the upper layer, with opposing velocities in the lower layer (order $1.1 \mathrm{~m} / \mathrm{s}$ ) and the nodal point around $120-\mathrm{m}$ depth in $350 \mathrm{~m}$ of water. The vertical velocities exceeded $0.5 \mathrm{~m} / \mathrm{s}$, downward at the head of the wave and upward behind. Inverse ray tracing suggests that the largest "transbasin" waves were generated in the Luzon Strait and refracted around Dong-Sha Island. These results were reinforced by the SAR imagery [15], [18], which clearly show these phenomena. Comparing the SAR and in situ data demonstrates that surface slick formation is a complex air/sea interaction problem: The waves with the largest surface signature were not the largest waves in situ.

Theoretical and numerical modeling of the high-frequency internal waves has only begun. The initial results suggest that moderate-amplitude $(A<\sim 80 \mathrm{~m})$ incoming waves can be reasonably modeled in deep water using EKdV theory but that the extremely large waves $(A>100 \mathrm{~m})$ cannot. [15], [22], [24]. Several continuing efforts are underway to model the transition in shallow water from depression to elevation waves. To acquire some level of predictive skill is important, given the large impact that the waves have on marine operations and acoustic propagation. The acoustic impacts are taken up in the next section of this paper. 


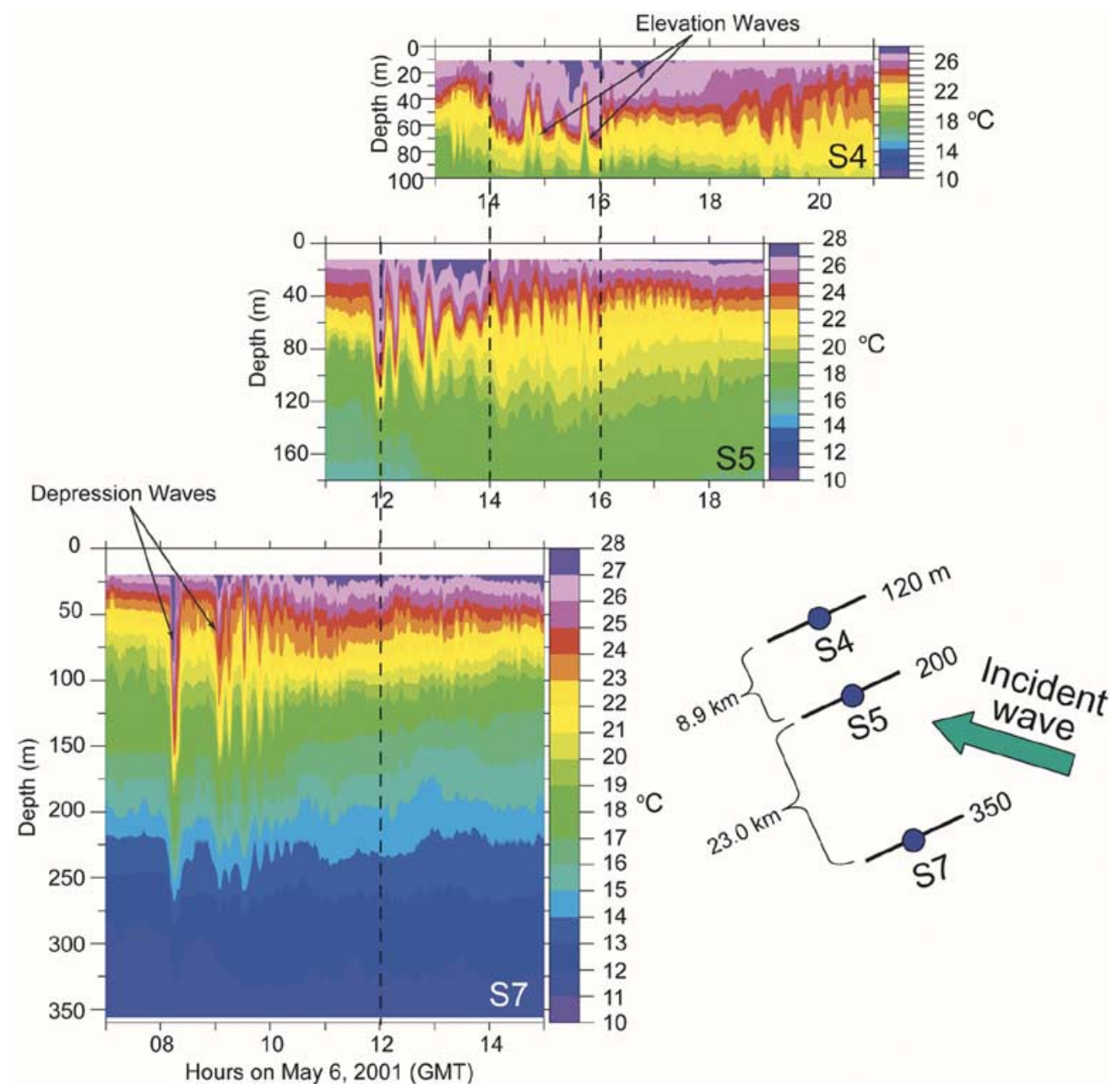

Fig. 1. Temperature structure of large amplitude internal waves on May 6, 2001, as they propagated into shallower water over the continental shelf and slope east of Dongsha Island. The time axes have been aligned as indicated by the dotted black lines.

\section{SUMMARY OF ACOUSTIC IMPACTS}

The specific objectives of the ASIAEX SCS acoustics component were

1) to understand the physics, variability, coherence, and predictability of low-frequency sound propagation along and across the northeastern (NE) SCS shelfbreak, including the dependence on frequency, source/receiver depth, and path orientation, and the relations to water-column, bathymetric, and subbottom structures;

2) to expand the acoustic knowledge acquired from previous shelf-edge experiments including SWARM and the Shelfbreak PRIMER, with added emphases on the horizontal properties of the sound field and the impact of severe environmental variability on the performance of signal processors (e.g., beamformers and matched-field processors) and ambient noise.

The great majority of the acoustic data were taken by an L-shaped hydrophone array moored on the shelf at the $120-\mathrm{m}$ isobath. Developed jointly by the Woods Hole Oceanographic
Institution (WHOI), Woods Hole, MA, and the Naval Postgraduate (NPS), Monterey, CA, this listening array consisted of 16 hydrophones moored vertically in the water column and 32 hydrophones spanning approximately half a kilometer horizontally along the sea floor. Sampling continuously at a rate of $3.2 \mathrm{kHz}$ over the first three weeks in May, these hydrophones monitored repetitive phase-modulated (PM) and linear frequency-modulated (LFM) signals transmitted from the fixed sources. Supplied by NPS, WHOI, and the Naval Research Laboratory (NRL), these fixed sources have transmission frequency bands centered at 224, 300, 400, and $500 \mathrm{~Hz}$ and were moored on a slope and a shelf location to define the across-shelf and along-shelf transmission path, respectively. In addition to the fixed-fixed transmissions, LFM signals spanning the 50-200, 240-260, and 550-600 $\mathrm{Hz}$ bands were transmitted from a towed J-15-3 source on three separate days, May 5, 16, and 17 (Fig. 2). The periods of operation for each of the acoustic instruments and the types of signal transmitted by each of the sound sources are summarized in Fig. 3. Of interest to note is that, besides the intended signals, there also was a 


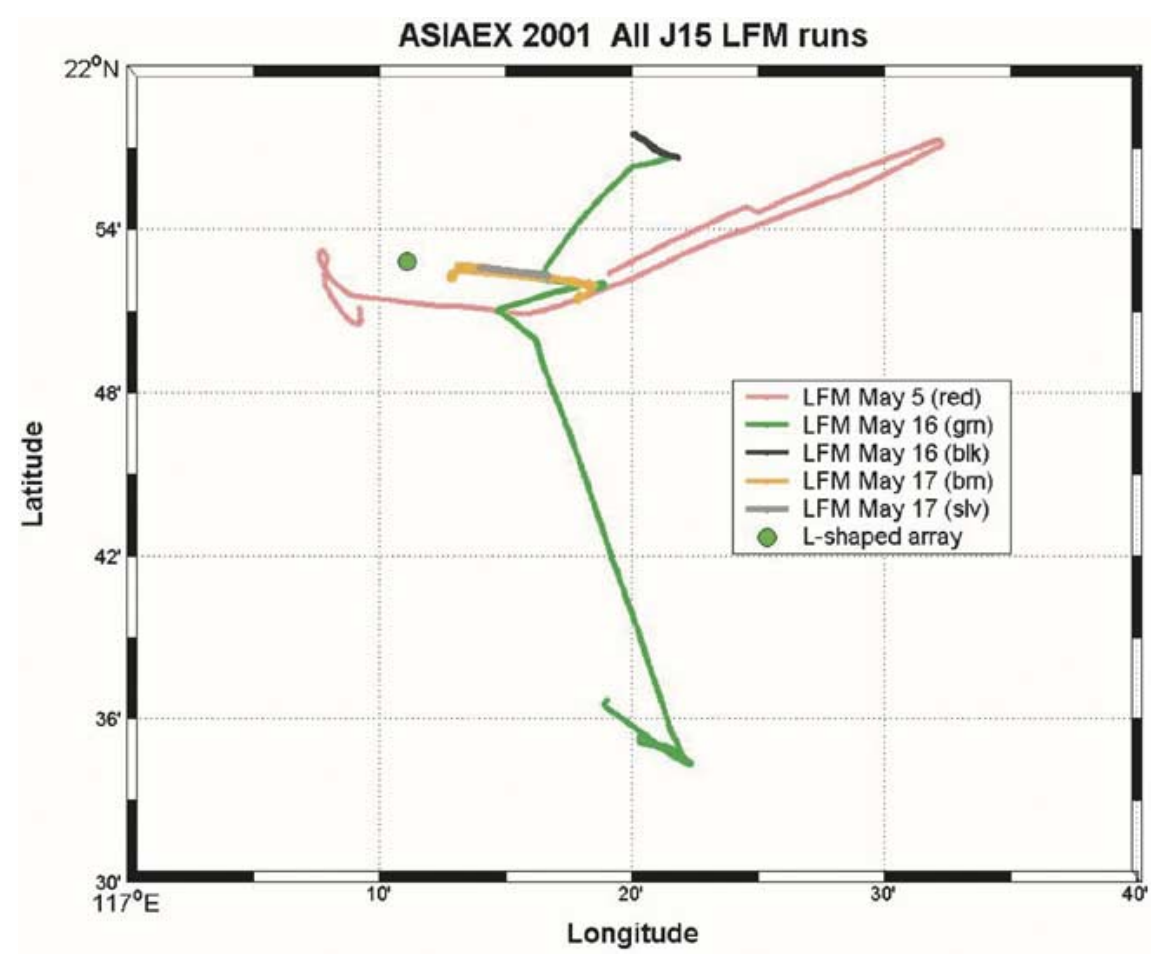

Fig. 2. Tracks of the towed J-15-3 sound source executed from the research vessel OR3.

large signal produced by an unidentified explosion nearby. This broadband "source of opportunity" was exploited by Liu et al. [25] to extract geoacoustic information.

As discussed in the oceanography section, sound-speed fluctuations of the SCS shelf-slope region in May 2001 were dominated by "transbasin" and local internal tides and by "transbasin" nonlinear internal waves. The shoaling water depth amplified the disturbances of these nonlinear internal waves as they evolved shoreward onto the shelf. The scattering of the transbasin waves by the nearby Dongsha Island [15] also contributed to the complexity of the acoustic problem. The impacts of these nonlinear internal waves on various aspects of the acoustic propagation are the subject of discussion in several papers in this volume. Pasewark et al. [26] investigated the impact on horizontal coherence and horizontal beamforming performance. Mignerey and Orr [27] studied the impact on matched-field processors and concluded that the SCS internal wave packets significantly shortened the lifetime of replica vectors and, thus, caused appreciable matched-field processor degradation. Duda et al. [28] examined the resultant characteristic features in the intensity-fluctuation time series and compared the signal statistics between the along- and cross-shelf paths. Chiu et al. [29] explained and contrasted the observed intensity fluctuations of the $400-\mathrm{Hz}$, across-shelf transmissions in two separate days having extreme environmental differences: On one day the passage of several huge solitons depressed the shallow isotherms to the sea bottom and on the other day had a much less energetic internal wavefield. Specifically, their interpretation of the observed changes in the vertical distribution of sound intensity was aided with coupled-mode propagation modeling facilitated with a space-time continuous, empirical representation of the sound-speed field.

The physical and acoustical properties of the sea bed were studied by Shock [30], [31] and Liu et al. [25], respectively, using newly formulated geoacoustic inversion methods. Schock's method was based on the Biot model and utilized normal incident reflection data from $(1-10 \mathrm{kHz})$ chirp sonar to infer the porosity, grain size, bulk density, permeability, and attenuation in the top layer [30]. Shock applied his method to the chirp-sonar survey data to generate imagery of the sediment layering and estimate of the sediment properties along the fixed-fixed acoustic transmission paths [31]. Schock's analysis of the upper-layer sediment structure was nicely complimented by a linear broadband inverse performed by Liu et al. [25] on the "broadband signal of opportunity." This explosive signal contained sufficiently low-frequency content $(5-500 \mathrm{~Hz})$ that probed the geoacoustic properties in the deeper layers.

Wei et al. [32] examined the low-frequency ambient noise field, its vertical and frequency dependences, and its temporal behavior using a two-week-long time series. Two interesting features in the observed noise were reported: 1) the appreciable increase in noise due to a typhoon, which passed near the experimental site and 2) the weak tidal frequency variability of the noise field, which was attributable to internal tide induced variability in the propagation conditions. 
April May

2829300102030405060708091011121314151617181920212223

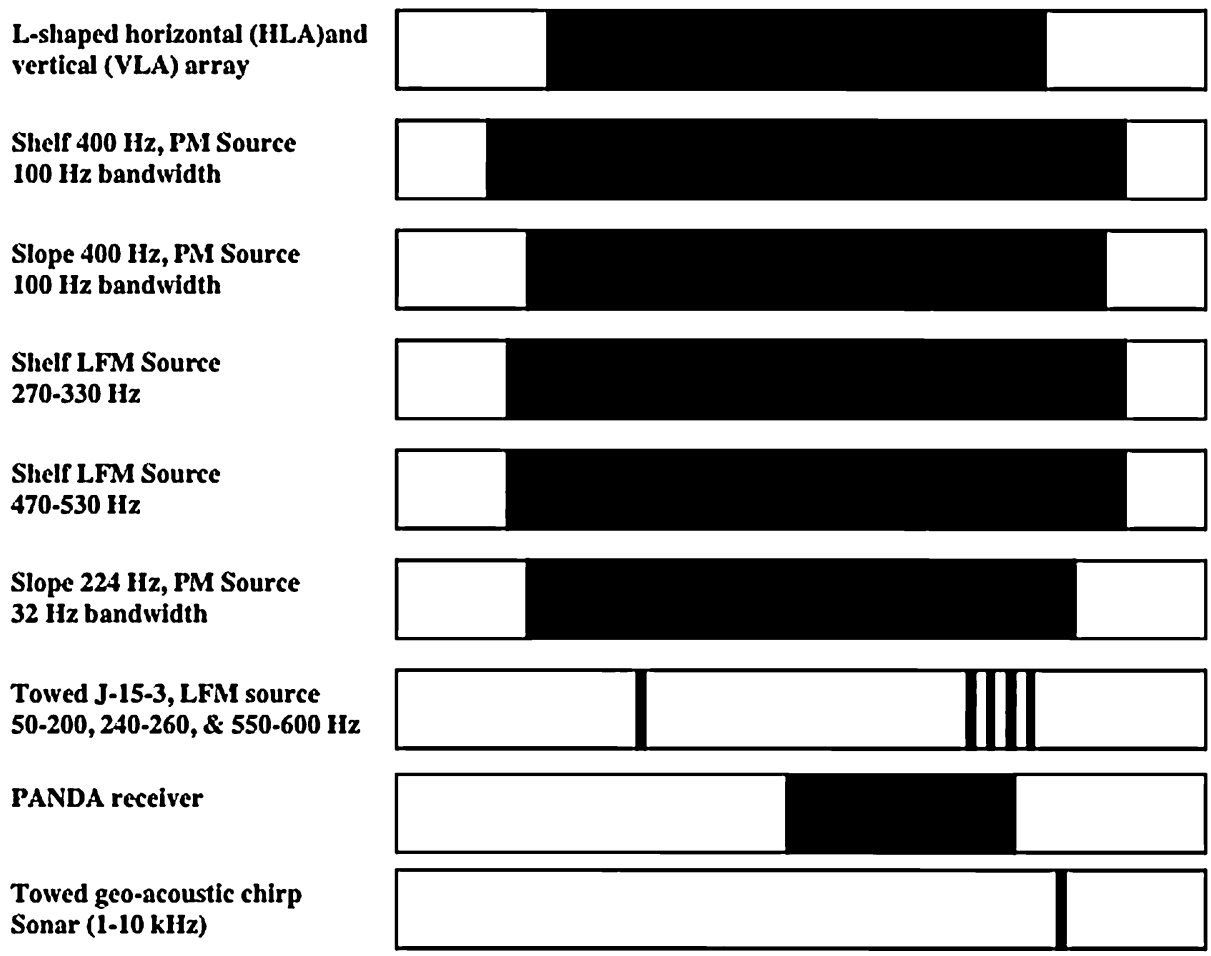

Fig. 3. Summary of operational timelines and signal characteristics for the acoustic instruments deployed in ASIAEX SCS.

\section{CONCLUSION}

The ASIAEX program brought together the financial and human resources necessary to make advances in the field of environmental acoustics. Building upon the theme established by ONR of conducting high-resolution field experiments in physical oceanography and acoustic propagation in the same place at the same time, the program improved our understanding of both the physical variability and its acoustic implications in the northeastern SCS. A significant limitation of the experiment was its short duration during the spring season. Additional work is needed to understand conditions in the fall and during the summer and winter monsoons. Nevertheless, the work presented in this special issue represents a major building block in the quest to understand the burgeoning field of shallow-water acoustics.

\section{ACKNOWLEDGMENT}

The work at sea was conducted from the Taiwanese research vessels Ocean Researcher 1, Ocean Researcher 3, and Fisheries Researcher 1. The skill and enthusiasm of the officers and crew of all these vessels is gratefully acknowledged. The planning, execution, and analysis of this work was funded by the U.S. Office of Naval Research Ocean Acoustics and Physical Oceanography Programs. Significant support was also made by the National Science Council of Taiwan.

\section{REFERENCES}

[1] P. H. Dahl, R. Zhang, J. H. Miller, L. R. Bartek, Z. Peng, S. R. Ramp, J.-X. Zhou, C.-S. Chiu, J. F. Lynch, J. A. Simmen, and R. C. Spindel, "An overview of results from the Asian seas international acoustics experiment in the East China Sea," IEEE J. Oceanic Eng., vol. 29, pp. 920-928, Oct. 2004.

[2] J. Apel, M. Badiey, C.-S. Chiu, S. Finnette, R. Headrick, J. Kemp, J. Lynch, A. Newhall, M. Orr, B. Pasewark, D. Tielbuerger, A. Turgut, K. von der Heydt, and S. Wolf, "An overview of the 1995 SWARM shallow water internal wave acoustic scattering experiment," IEEE J. Oceanic Eng., vol. 22, pp. 465-500, July 1997.

[3] J. F. Lynch, A. E. Newhall, B. Sperry, G. Gawarkiewicz, A. Fredricks, P. Tyack, C.-S. Chiu, and P. Abbot, "Spatial and temporal variations in acoustic propagation characteristics at the New England shelfbreak front," IEEE J. Oceanic Eng., vol. 28, pp. 129-150, Jan. 2003.

[4] S. Hellerman and M. Rosenstein, "Normal monthly wind stress over the world ocean with error estimates," J. Phys. Oceanogr., vol. 13, pp. 1093-1104, 1983.

[5] P.-T. Shaw, "The intrusion of water masses into the sea southwest of Taiwan,” J. Geophys. Res., vol. 94, pp. 18213-18226, 1989.

[6] E. J. Metzger and H. E. Hurlburt, "Coupled dynamics of the south China sea, the Sulu sea, and the Pacific ocean," J. Geophys. Res., vol. 101, pp. 12331-12352, 1996.

[7] A. L. Ye and I. S. Robinson, "Tidal dynamics in the south China sea," Geophys. J. R. Astron. Soc., vol. 72, pp. 691-707, 1983.

[8] P. Mazzega and M. Berge, "Ocean tides in the Asian semi-enclosed seas from TOPEX/POSEIDON," J. Geophys. Res., vol. 99, pp. 24867-24881, 1994.

[9] T. Hatayama, T. Awaji, and K. Akitomo, "Tidal currents in the Indonesian seas and their effect on transport and mixing," J. Geophys. Res., vol. 101, pp. 12353-12373, 1996.

[10] G. Fang, "A two-dimensional numerical model for tidal motion in the Taiwan strait," Marine Geophys. Res., vol. 7, pp. 267-276, 1984.

[11] G. Fang, Y.-K. Kwok, K. Yu, and Y. Zhu, "Numerical simulation of principal tidal constituents in the South China Sea, Gulf of Tonkin and Gulf of Thailand," Continental Shelf Res., vol. 19, pp. 845-869, 1999. 
[12] C. C. Ebbesmeyer, C. A. Coomes, R. C. Hamilton, K. A. Kurrus, T. C. Sullivan, B. L. Salem, R. D. Romea, and R. J. Bauer, "New observations on internal waves (solitons) in the south China sea using an acoustic Doppler current profiler," in Proc. Marine Technology Soc., New Orleans, LA, 1991, pp. 165-175.

[13] J. B. Bole, C. C. Ebbesmeyer, and R. D. Romea, "Soliton currents in the south China sea: Measurements and theoretical modelling," in Proc. 26th Annu. Offshore Technology Conf. (OTC), Houston, TX, 1994, pp. 367-376.

[14] M.-K. Hsu and A. K. Liu, "Nonlinear internal waves in the south China sea," Can. J. Remote Sensing, vol. 26, pp. 72-81, 2000.

[15] S. R. Ramp, T.-Y. Tang, T. F. Duda, J. F. Lynch, A. K. Liu, C.-S. Chiu, F. Bahr, H.-R. Kim, and Y. J. Yang, "Internal solitons in the northwestern South China Sea part I: Sources and deep water propagation," IEEE J. Oceanic Eng., vol. 29, pp. 1157-1181, Oct. 2004.

[16] G. Gawarkiewicz, J. Wang, M. Caruso, S. R. Ramp, K. Brink, and F. Bahr, "Shelfbreak circulation and thermohaline structure in the northern south China sea: Contrasting spring conditions in 2000 and 2001," IEEE J. Oceanic Eng., vol. 29, pp. 1131-1143, Oct. 2004.

[17] M. H. Orr and P. C. Mignerey, "Nonlinear internal waves in the south China sea: Observation of the conversion of depression internal waves to elevation internal waves," J. Geophys. Res., vol. 108, p. 3 064, 2003.

[18] A. K. Liu, Y. Zhao, T. Y. Tang, and S. R. Ramp, "A case study of internal wave propagation during ASIAEX-2001," IEEE J. Oceanic Eng., vol. 29 , pp. 1144-1156, Oct. 2004.

[19] Y. Hsueh and L. Zhong, "A note on the deflection of a baroclinic current by a continental shelf," Geophys. Astrophys. Fluid Dynam., vol. 97, pp. 393-415, 2003.

[20] R. C. Beardsley, T. F. Duda, J. D. Irish, and S. R. Ramp, "The barotropic tide in the northeast South China Sea," IEEE J. Oceanic Eng., vol. 29, pp. 1075-1086, Oct. 2004

[21] F. Lefevre, C. Le Provost, and F. H. Lyard, "How can we improve a global ocean tide model at a regional scale? A test on the Yellow Sea and the East China Sea," J. Geophys. Res., vol. 105, pp. 8707-8725, 2000.

[22] T. F. Duda, J. F. Lynch, J. D. Irish, R. C. Beardsley, S. R. Ramp, C.-S. Chiu, T.-Y. Tang, and Y.-J. Yang, "Internal tide and nonlinear internal wave behavior at the continental slope in the northern South China Sea," IEEE J. Oceanic Eng., vol. 29, pp. 1105-1130, Oct. 2004.

[23] Y. Niwa and T. Hibiya, "Numerical study of the spatial distribution of the M2 internal tide in the Pacific ocean," J. Geophys. Res., vol. 106, no. C10, pp. 22441-22449, 2001.

[24] Y.-J. Yang, T.-Y. Tang, and S. R. Ramp, "Solitons northeast of Tung-Sha island during the ASIAEX pilot studies," IEEE J. Oceanic Eng., vol. 29, pp. 1182-1199, Oct. 2004.

[25] Y. T. Lin, J. F. Lynch, N. Chotiros, C.-F. Chen, A. Newhall, A. Turgut, S. Schock, C.-S. Chiu, L. Bartek, and C.-S. Liu, "An estimate of the bottom compressional wave profile in the northeastern South China Sea using sources of opportunity," IEEE J. Oceanic Eng., vol. 29, pp. 1231-1248, Oct. 2004.

[26] B. H. Pasewark, S. N. Wolf, M. H. Orr, J. F. Lynch, and T. Schroeder, "Impact of the oceanographic environment on acoustic signal correlation and beamformer performance in ASIAEx 2001, South China Sea component," IEEE J. Oceanic Eng., to be published.

[27] P. C. Mignerey and M. H. Orr, "Observations of matched-field autocorrelation time in the South China Sea," IEEE J. Oceanic Eng., vol. 29, pp. 1280-1292, Oct. 2004.

[28] T. F. Duda, J. F. Lynch, L. Wu, and C.-S. Chiu, "Fluctuation of 400 $\mathrm{Hz}$ sound intensity in the 2001 ASIAEX South China Sea experiment," IEEE J. Oceanic Eng., vol. 29, pp. 1264-1279, Oct. 2004.

[29] C.-S. Chiu, S. R. Ramp, C. W. Miller, J. F. Lynch, T. F. Duda, and T.-Y. Tang, "Acoustic intensity fluctuations induced by south China sea internal tides and solitons," IEEE J. Oceanic Eng., vol. 29, pp. 1249-1263, Oct. 2004.

[30] S. G. Schock, "A method for estimating the physical and acoustic properties of the seabed using chirp sonar data," IEEE J. Oceanic Eng., vol. 29 , pp. 1200-1217, Oct. 2004.

[31] _ - "Remote prediction of physical and acoustic sediment properties in south China sea using chirp sonar data and the Biot model," IEEE J. Oceanic Eng., vol. 29, pp. 1218-1230, Oct. 2004.

[32] R.-C. Wei, C.-F. Chen, A. E. Newhall, J. F. Lynch, and C.-S. Liu, "A preliminary examination of the low-frequency ambient noise field in the South China Sea during the 2001 ASIAEX experiment," IEEE J. Oceanic Eng., vol. 29, pp. 1308-1315, Oct. 2004.

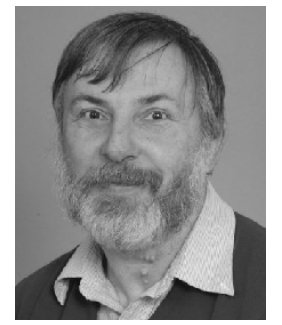

James F. Lynch (M'96-SM'03) was born in Jersey City, NJ, on June 3, 1950. He received the B.S. degree in physics from Stevens Institute of Technology, Hoboken, NJ, in 1972 and the Ph.D. degree in physics from the University of Texas, Austin, in 1978.

He was with the Applied Research Laboratories, University of Texas at Austin (ARL/UT) from 1978 to 1981 , after which he joined the scientific staff at the Woods Hole Oceanographic Institution (WHOI), Woods Hole, MA. He has been with WHOI since then and currently holds the position of Senior Scientist in the Applied Ocean Physics and Engineering Department. His research specialty areas are ocean acoustics and acoustical oceanography, but he also greatly enjoys occasional forays into physical oceanography, marine geology, and marine biology.

Dr. Lynch is a Fellow of the Acoustical Society of America and Editor-inChief of the IEEE JOURNAL OF OCEANIC ENGINEERING.

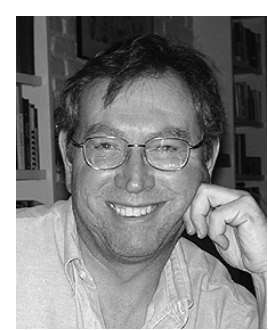

Steven R. Ramp received the M.S. degree in physical oceanography from the University of Washington, Seattle, in 1976, and the Ph.D. degree in physical oceanography from the University of Rhode Island, Narragansett, in 1986.

Since 1986, he has been with the U.S. Navy as a Professor at the Naval Postgraduate School, Monterey, CA, and a Program Officer at the Office of Naval Research, Arlington, VA. Prior to this, he spent time at the National Marine Fisheries Service, Woods Hole, MA. His research specialty is ocean observations from both ships and oceanographic moorings, and he has organized major expeditions to the Japan Sea, East China Sea, and South China Sea. He was the International Scientific Coordinator for the Asian Seas International Acoustics Experiment (ASIAEX).

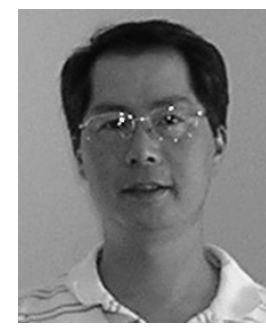

Ching-Sang Chiu received the Ph.D. degree from the Massachusetts Institute of Technology/Woods Hole Oceanographic Institution, Woods Hole, MA (MIT-WHOI) joint program in 1985.

$\mathrm{He}$ is a Professor of oceanography with the Naval Postgraduate School. His research specialties include ocean acoustics, acoustical oceanography, and coastal ocean processes and their influences on acoustics prediction. He has authored or coauthored more than 40 refereed publications in those subject areas.

Dr. Chiu is a Fellow of the Acoustical Society of America and Editor-in-Chief of the Journal of Computational Acoustics.

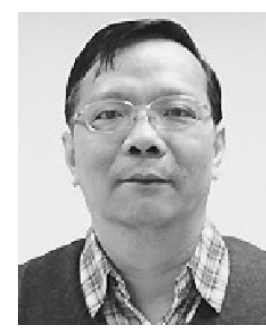

Tswen Yung Tang was born in Taiwan in 1952. He received the M.S. degree in physical oceanography from National Taiwan University, Taiwan, in 1975 and the Ph.D. degree in physical oceanography from North Carolina State University, Raleigh, in 1984.

In August 1993, he was appointed Professor of Physical Oceanography at the Institute of Oceanography, National Taiwan University. He was appointed Program Manager of the Division of Marine Science, National Science Council, Taiwan, in January 2004. His research interests include equatorial dynamics, variability of upstream of Kuroshio, Kuroshio intrusion at Luzon Strait, circulation in the South China Sea, and internal waves. 


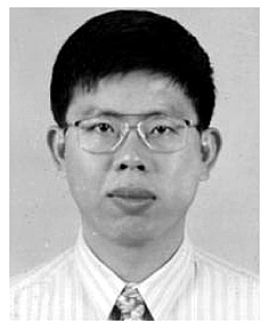

physical Union.
Ying-Jang Yang was born in Taiwan in 1967. He received the B.S. degree in oceanography and the Ph.D. degree in physical oceanography from the National Taiwan University, Taipei, Taiwan, in 1990 and 1996, respectively.

He currently is an Assistant Professor with the Department of Marine Science, Chinese Naval Academy, Kaohsiung, Taiwan. His research interests include internal tides and waves, current variation around Taiwan, and equatorial dynamics.

Dr. Yang is a Member of the American Geo-

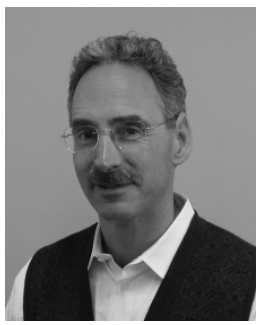

Jeffrey A. Simmen received the Ph.D. degree in applied mathematics from the California Institute of Technology, Pasadena, in 1984.

$\mathrm{He}$ was with the Center for Naval Analyzes (CNA), Alexandria, VA, on operations research and tactical development for submarine and antisubmarine warfare operations for the following five years. While with the CNA, he spent two years on assignment in Italy at the submarine command COMSUBGRUEIGHT. In 1989, he joined the Naval Postgraduate School, Monterey, CA, and the University of California, Santa Cruz, respectively, for the next few years, where he taught and conducted research in fluid dynamics and ocean acoustics. In 1993, he joined the Office of Naval Research, Washington, DC, where he managed a basic and applied research program in ocean acoustics. In 2003, he became the seventh Director of the Applied Physics Laboratory, University of Washington, Seattle. His research interests include sound propagation through internal waves and fluctuations in high-frequency acoustics. 